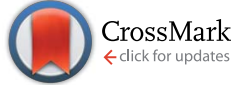

Cite this: J. Mater. Chem. A, 2014, 2, 18742

Received 25th August 2014 Accepted 24th September 2014

DOI: $10.1039 / c 4 t a 04385 e$

www.rsc.org/MaterialsA

\section{High performance perovskite solar cells by hybrid chemical vapor deposition $\uparrow$}

\author{
Matthew R. Leyden, Luis K. Ono, Sonia R. Raga, Yuichi Kato, Shenghao Wang \\ and Yabing Qi*
}

\begin{abstract}
Organometal halide based perovskites are promising materials for solar cell applications and are rapidly developing with current devices reaching $\sim 19 \%$ efficiency. In this work we introduce a new method of perovskite synthesis by hybrid chemical vapor deposition (HCVD), and demonstrate efficiencies as high as $11.8 \%$. These cells were found to be stable with time, and retained almost the same efficiency after approximately $1100 \mathrm{~h}$ storage in dry $\mathrm{N}_{2}$ gas. This method is particularly attractive because of its ability to scale up to industrial levels and the ability to precisely control gas flow rate, temperature, and pressure with high reproducibility. This is the first demonstration of a perovskite solar cell using chemical vapor deposition and there is likely still room for significant optimization in efficiency.
\end{abstract}

\section{Introduction}

Organometal halide perovskite based solar cells have been rapidly improving in recent years. In 2009 efficiencies were around $4 \%,{ }^{1}$ but in 5 years time that number has more than quadrupled to $\sim 19 \% .^{2-6}$ Due to perovskite's broad spectral absorbance, low temperature processing, and low cost of materials it is a promising material for low cost solar cells. To achieve easier fabrication and better reproducibility, we used a two-step method of perovskite synthesis where a layer of metal halide (e.g. $\mathrm{PbCl}_{2}$ and $\mathrm{PbI}_{2}$ ) is deposited, followed by the addition of an ammonium halide salt (e.g. methyl ammonium iodide, formamidinium bromide). In this method, a solid powder is converted to the gas phase in a dedicated zone of the tube furnace and then deposited onto substrates downstream in another zone of the tube furnace. Because of the use of solid precursors, this method can be viewed as a form of hybrid chemical vapor deposition (HCVD). Two-step processes where methyl ammonium halide is deposited by spin coating or vapor phase can reach efficiency as high as $15 \% .{ }^{7-11}$ Perovskite has

Energy Materials and Surface Sciences Unit, Okinawa Institute of Science and Technology Graduate University, 1919-1 Tancha, Onna-son, Okinawa, 904-0495, Japan. E-mail: yabing.qi@oist.jp

$\dagger$ Electronic supplementary information (ESI) available. See DOI: 10.1039/c4ta04385e been previously synthesized by $\mathrm{CVD},{ }^{12,13}$ but this work is the first to use CVD to demonstrate any solar cell efficiency. The reported stability of perovskite films can vary significantly. In one case, perovskite is reported to decay substantially to $20 \%$ of its original performance over the course of 6 days in a $\mathrm{N}_{2}$ environment, ${ }^{6}$ and in others it is reported to be stable for $500 \mathrm{~h}$ in air without encapsulation. ${ }^{\mathbf{1 4}}$

Perovskite solar cells made by HCVD were shown to be stable up to $1100 \mathrm{~h}$ in a $\mathrm{N}_{2}$ environment, which warrants further study of stability under ambient conditions.

\section{Results and discussion}

Multi-zone HCVD has independent precise control of pressure, gas flow rate, methyl ammonium iodide (MAI) temperature, and substrate temperature, which helps improve reproducibility and performance. For example, by controlling the pressure $(1 \mathrm{~Pa}$ to $1 \mathrm{~atm})$, the diffusion rate $\left(D_{\mathrm{g}} \propto T^{3 / 2} / P\right.$, where $D_{\mathrm{g}}$ is the gas diffusion constant, $T$ is the temperature, and $P$ is the pressure $)^{15}$ can be varied over a wide range, which is expected to provide more flexibility in controlling the film growth and possibly will lead to higher performance. The easy but rigorous process control and capacity to fabricate large uniform films is also expected to facilitate scale-up. In this work, perovskite is fabricated by a two-step method where lead chloride is first deposited onto appropriate substrates by thermal evaporation in high vacuum, followed by vapor phase deposition of MAI using HCVD. Lead chloride is used because it was observed to produce a more uniform film by evaporation than $\mathrm{PbI}_{2}$, and is reported to increase the charge diffusion length in perovskite films. ${ }^{16,17}$ It is expected that other metal halide precursors prepared by vacuum evaporation or solution processing are also compatible with our HCVD method. For example, a solution based method of $\mathrm{PbI}_{2}$ deposition was used with HCVD and it demonstrated some efficiency. Fig. 1a shows an example of the HCVD deposition process, in which $\mathrm{PbCl}_{2}$ and MAI are used. The substrates (fluorine doped tin oxide (FTO) glass substrate/ $/ \mathrm{TiO}_{2}$ compact layer pre-deposited with $\mathrm{PbCl}_{2}$ ) and MAI are loaded into two 


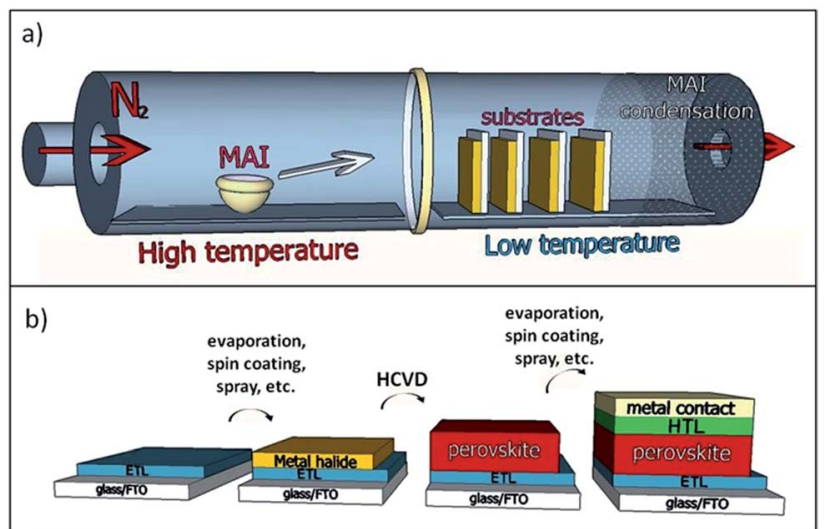

Fig. 1 Hybrid chemical vapor deposition based perovskite synthesis (a) diagram of the HCVD furnace and MAI deposition onto metal halide seeded substrates. (b) Layered structure of a complete solar cell fabricated by a HCVD process. The complete solar cell is a glass substrate followed by a FTO layer, an electron transport layer, a perovskite layer, a hole transport layer, and a top metal contact.

separate temperature control zones of the furnace. The furnace is then sealed, pumped down to a certain pressure and purged with inert gas. The diffusion of MAI takes place in two phases. First the MAI must diffuse to the substrate in the gas phase $\left(D_{\mathrm{g}} \propto T^{3 / 2} / P\right)$. Once the MAI has landed onto the substrate it must diffuse through the film (i.e., solid diffusion) to react with the metal halide present at the bottom surface. In the case of solid diffusion, the diffusion constant is determined by the Arrhenius equation $\left(D_{\mathrm{s}} \propto \mathrm{e}^{-C / k T}\right.$, where $D_{\mathrm{s}}$ is the gas diffusion constant, $C$ is a constant, $k$ is Boltzmann's constant). ${ }^{18}$ Higher temperatures will increase both gas and solid diffusion rates, and increase the speed of perovskite conversion.

A schematic diagram of a complete solar cell and the layers within is shown in Fig. 1b. The electron transport layer (ETL) of the cell is FTO coated with a thin film of titanium oxide made by spray pyrolysis. This is followed by the deposition of a metal halide layer and HCVD perovskite synthesis. The hole transport layer (HTL) is a film of spiro-MeOTAD spun onto the perovskite surface followed by gold top electrode deposition via evaporation. A photograph of a complete, functioning device is shown
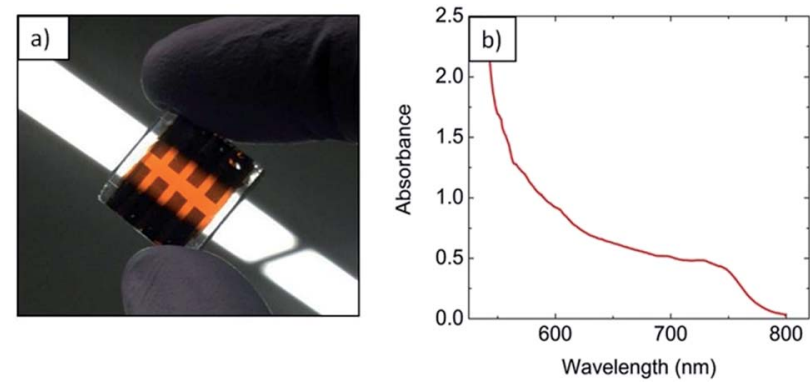

Fig. 2 Transmission through the complete perovskite solar cell. (a) Back view of the complete HCVD solar cell with front illumination from a fluorescent light bulb; (b) UV-vis spectrum of a complete cell showing an absorption edge at $781 \mathrm{~nm}$. in Fig. 2a. From this image, we can see that the film is partially transparent and homogeneous. The absorbance spectrum was taken on a complete device (Fig. 2b) and the absorption edge was measured to be at $781 \mathrm{~nm}$ (ref. 14) making it suitable for applications like photovoltaic windows and multi-junction solar cells. $^{19}$

The furnace zone with MAI was heated to $185{ }^{\circ} \mathrm{C}$, and the zone with the substrate was heated to a nominal temperature of $130{ }^{\circ} \mathrm{C}$. Due to the flow of hot gas, the temperature inside the growth region is a gradient between the two set temperatures. Specifically, substrates were usually loaded in the region that reaches a maximum temperature between $160{ }^{\circ} \mathrm{C}$ and $170{ }^{\circ} \mathrm{C}$. Samples that were placed in a region hotter than $170{ }^{\circ} \mathrm{C}$ were not observed to correctly form perovskite. The initial $\mathrm{PbCl}_{2}$ layer was converted into a yellow film of $\mathrm{PbI}_{2}$ in the high temperature regions of the furnace (ESI, Fig. $\mathrm{S} 1 \dagger$ ). This suggests that the substrate temperature was too high, and that there is a maximum temperature of perovskite formation around $170{ }^{\circ} \mathrm{C}$. Substrates that were loaded in zones with a maximum temperature of $145{ }^{\circ} \mathrm{C}$ were found to be unstable. Perovskite formed at this temperature rapidly turned transparent when exposed to air. Independent control of temperature zones and control of pressure provide significant advantages over existing vapor deposition methods. ${ }^{9}$ The additional degree of control may open the door for fabrication of a wider range of perovskite materials.

Thermal evaporation was used to deposit the metal halide layer because it offers good uniformity and thickness control. The resulting perovskite films show a relatively smooth morphology with complete coverage (RMS roughness $=28 \pm 10 \mathrm{~nm}$, on
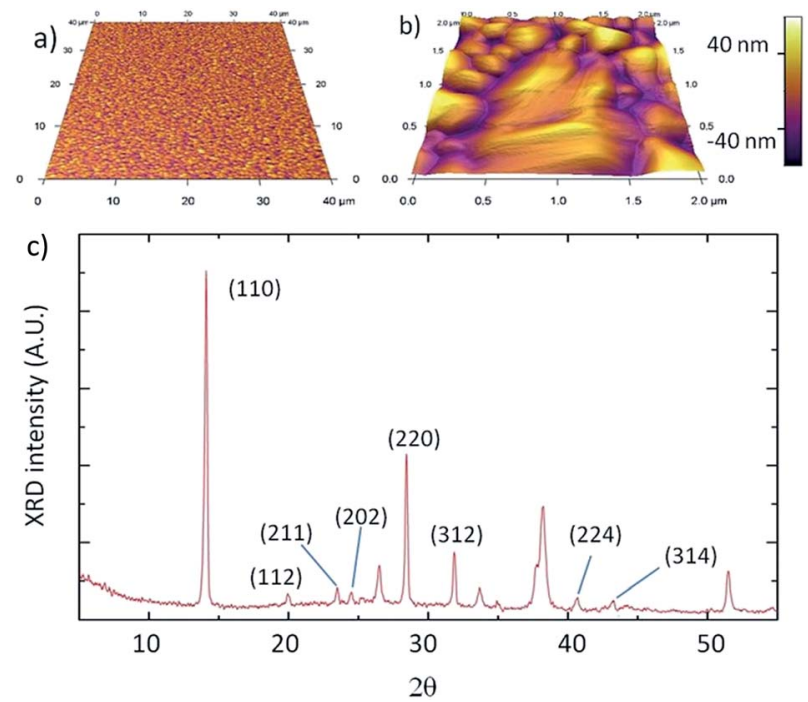

Fig. 3 Analysis of perovskite films. (a and b) Atomic force microscopy 3D images of the perovskite thin film on the silicon substrate in true proportion. The silicon substrate was prepared under the same conditions and at the same time as those used for the highest performing device. (a) $40 \times 40 \mu \mathrm{m}^{2}$ scan of a perovskite film with $18 \mathrm{~nm}$ RMS roughness. (b) $2 \times 2 \mu \mathrm{m}^{2}$ image showing the laminate structure of the perovskite grains. (c) X-ray diffraction spectrum of the working perovskite solar cell. The major perovskite peaks $(110)$ at $14.1^{\circ}$, and (220) at $28.4^{\circ}$ are clearly shown. 
silicon). Fig. 3a and b show AFM images of perovskite films in true proportions (i.e., the lengths along the lateral and vertical directions have the same scale). This surface roughness is similar to the roughness of the $\mathrm{FTO} / \mathrm{TiO}_{2}$ substrates used for solar cells $(\sim 27 \mathrm{~nm})$. A perovskite film on the $\mathrm{FTO} / \mathrm{TiO}_{2}$ substrate was measured to have a roughness of $\sim 50 \mathrm{~nm}$. In contrast, solar cells that are fabricated by a solution process often leads to incomplete coverage, and consequently a much higher roughness. ${ }^{20}$ Having lower surface roughness allows for thinner films on top of the perovskite, such as the hole transport layer and metal contact layer, which likely will lead to better optimized devices. Also in this work, the two top films correspond to the most expensive materials used, and having thinner films may help reduce manufacturing cost. The grains of perovskite films prepared by HCVD are typically between 0.2 and $2 \mu \mathrm{m}$ in size, with an average size of approximately $0.6 \pm 0.4 \mu \mathrm{m}$.

It appears that $\mathrm{PbCl}_{2}$ is mostly converted to perovskite during the CVD process. Film thicknesses are measured before and after the CVD deposition process and it is found to increase by a factor of $3.0 \pm 0.2$. It is possible to make an estimate of the thickness increase of fully converted perovskite assuming densities of lead chloride and perovskite to be $5.85 \mathrm{~g} \mathrm{~cm}^{-3}$ and $4.17 \mathrm{~g} \mathrm{~cm}^{-3}$, respectively. ${ }^{21}$ With these assumed densities, the expected volume would increase by a factor of 3.1, which is in good agreement with measured values and indicates that the perovskite is fully converted. Fig. 3c shows the X-ray diffraction (XRD) spectrum of the perovskite film and the observed characteristic diffraction peaks at $14^{\circ}$ and $28.4^{\circ}$ correspond to the (110) and (220) planes. The spectrum also reveals the presence of other orientations: $(112)$ at $20.0^{\circ},(211)$ at $23.5^{\circ},(202)$ at $24.5^{\circ}$, $(312)$ at $32.0^{\circ},(224)$ at 40.6 , and $(314)$ at $43.2^{\circ} .^{22}$ There are also peaks associated with the substrate, which are predominately due to SnO and are found at $26.5^{\circ}, 33.7^{\circ}, 37.9^{\circ}$, and $51.5^{\circ}$. The relatively high intensity of peaks at orientations other than (110) and (220) suggests that perovskite films grown by HCVD are not highly oriented with respect to the substrate, which appears consistent with the AFM image in Fig. 3a. For some perovskite samples, X-ray diffraction spectra reveal a peak at $12.6^{\circ}$ associated with the presence of $\mathrm{PbI}_{2}$. If present, these peaks are generally smaller compared to the main (110) perovskite peak, indicating that the resulting film mainly consists of perovskite.

One of the most important parameters observed is the thickness of the pre-deposited $\mathrm{PbCl}_{2}$ layer and subsequent perovskite. The average performance of solar cells with different $\mathrm{PbCl}_{2}$ layer thicknesses is shown in Fig. 4a. There appears to be a peak in efficiency at $\mathrm{PbCl}_{2}$ layer thickness approximately 100 $\mathrm{nm}$, or approximately $300 \mathrm{~nm}$ of perovskite. It has recently been proposed that lower open-circuit voltage $\left(V_{\mathrm{oc}}\right)$ and fill factor $(\mathrm{FF})$ observed for solar cell devices with a perovskite film thickness in excess of $300 \mathrm{~nm}$ can be due to the low hole mobilities of the electron blocking layer. ${ }^{23}$ Alternatively, poor performance with thick films may be due to perovskite grains smaller than the thickness of the film. ${ }^{24}$ This trend is most clearly observed when considering the fill factor as a function of thickness (ESI, Fig. S2 $\dagger$ ). Furthermore, it was found that post annealing substrates in air rather than in $\mathrm{N}_{2}$ significantly improves $V_{\mathrm{oc}}$, short-circuit current density $\left(J_{\mathrm{sc}}\right)$, and FF. The surface
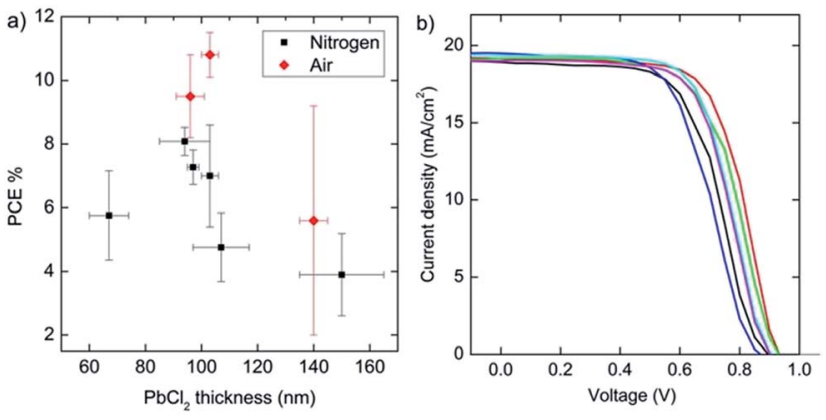

Fig. 4 Perovskite solar cell performance. (a) Efficiency as a function of film thickness. Scatter plot of average efficiencies of solar cells at different seed layer thicknesses. Black dots represent cells that were annealed in $\mathrm{N}_{2}$ and the red diamonds represent cells that were annealed in air. (b) $I-V$ measurements on the top performing batch of solar cells. The cells have $\sim 300 \mathrm{~nm}$ of perovskite grown by HCVD. The curves shown were measured $\sim 500 \mathrm{~h}$ after device fabrication.

morphology after air annealing was observed to be different than surfaces annealed in a $\mathrm{N}_{2}$ environment. It is very likely that the effect we observe in this work is similar to the solvent annealing effects as reported recently by Xiao et al. ${ }^{24} \mathrm{~A}$ set of air annealed solar cells, including the best performing cell demonstrated, is shown in Fig. 4b. This batch of solar cells had an average measured $\mathrm{PbCl}_{2}$ thickness of $103 \pm 3 \mathrm{~nm}$ and an average measured perovskite thickness of $296 \pm 4 \mathrm{~nm}$. The devices from this batch annealed in $\mathrm{N}_{2}$ had an average efficiency of $6.1 \%$ and a maximum of $8.8 \%$, while the devices annealed in air had an average efficiency of $10.8 \%$, and a maximum of $11.8 \%$.

To monitor the stability of perovskite solar cells made by HCVD, some samples were measured after 450-1100 h of storage in a $\mathrm{N}_{2}$ glove box. On average, the cells maintained their efficiency (ESI, Fig. S3†). For example, the highest performing sample was measured about $1100 \mathrm{~h}$ after the initial measurement and was found to have similar efficiency to the original measurement. After $1100 \mathrm{~h}$, the cell's $V_{\text {oc }}$ decreased slightly $(-1 \%)$ but $J_{\mathrm{sc}}(+2 \%)$ and $\mathrm{FF}(+5 \%)$ increased. The solar cell performance measurements were performed in ambient air with a temperature of $\sim 25{ }^{\circ} \mathrm{C}$ and a relative humidity of $\sim 50 \%$. Between the measurements, the samples were stored in the dark, inside a $\mathrm{N}_{2}$ glove box with $\mathrm{H}_{2} \mathrm{O}$ and $\mathrm{O}_{2}$ levels less than $0.1 \mathrm{ppm}$. The cell has spent a total of approximately $8 \mathrm{~h}$ outside of the $\mathrm{N}_{2}$ glove box for measurements. The stability observed in our solar cells is likely related to the fact that perovskite in our HCVD method reaches temperatures above $160{ }^{\circ} \mathrm{C}$. At a temperature above $160{ }^{\circ} \mathrm{C}$, excess MAI and incorporated water are expected to evaporate completely. The HCVD process forms perovskite with a constant flow of MAI and may be prone to absorb excess MAI. A film of MAI is hygroscopic and will likely cause instability issues. Thermogravimetric analysis shows that a MAI powder sample starts to lose mass at $145^{\circ} \mathrm{C}$ (ESI, Fig. S4 $\dagger$ ). This is consistent with the observation that the minimum temperature of stable perovskite formation is higher than $145^{\circ} \mathrm{C}$.

Similar to perovskite solar cells that are fabricated with other methods, devices fabricated by HCVD suffer from hysteresis. ${ }^{22}$ 
The top performing cell showed substantially lower (7.0\%) efficiency when measured in the reverse bias (ESI, Fig. S5 $\dagger$ ). Further optimization of parameters such as layer thickness, MAI deposition temperature and time, and annealing conditions could yield performance similar to those of the highest performing solar cells, but is beyond the scope of this study.

\section{Experimental}

Details involving synthesis, fabrication and measurement are included in the ESI. $\dagger$

\section{Conclusions}

To summarize, we developed a new method of perovskite synthesis by hybrid chemical vapor deposition (HCVD). The solar cells fabricated by this method not only achieved efficiencies as high as $\mathbf{1 1 . 8 \%}$, but also exhibited decent stability showing almost the same efficiency after approximately $1100 \mathrm{~h}$ storage in dry $\mathrm{N}_{2}$ gas. HCVD is of particular advantage due to its ability to scale up to industrial levels and the ability to precisely control gas flow rate, temperature, and pressure with high reproducibility. It is expected that process optimization of HCVD can further improve performance.

\section{Acknowledgements}

The authors would like to acknowledge the financial support from the Okinawa Institute of Science and Technology Graduate University in Japan.

\section{References}

1 A. Kojima, K. Teshima, Y. Shirai and T. Miyasaka, J. Am. Chem. Soc., 2009, 131, 6050-6051.

2 M. Liu, M. B. Johnston and H. J. Snaith, Nature, 2013, 501, 395-398.

3 J. Burschka, N. Pellet, S.-J. Moon, R. Humphry-Baker, P. Gao, M. K. Nazeeruddin and M. Grätzel, Nature, 2013, 499, 316319.

4 J. T.-W. Wang, J. M. Ball, E. M. Barea, A. Abate, J. A. Alexander-Webber, J. Huang, M. Saliba, I. Mora-Sero, J. Bisquert, H. J. Snaith and R. J. Nicholas, Nano Lett., 2014, 14, 724-730.

5 C.-H. Chiang, Z.-L. Tseng and C.-G. Wu, J. Mater. Chem. A, 2014, DOI: 10.1039/C4TA03674C.

6 H. Zhou, Q. Chen, G. Li, S. Luo, T. Song, H.-S. Duan, Z. Hong, J. You, Y. Liu and Y. Yang, Science, 2014, 345, 542-546.
7 H. Hu, D. Wang, Y. Zhou, J. Zhang, S. Lv, S. Pang, X. Chen, Z. Liu, N. P. Padture and G. Cui, RSC Adv., 2014, 4, 2896428967.

8 J. Burschka, N. Pellet, S.-J. Moon, R. Humphry-Baker, P. Gao, M. K. Nazeeruddin and M. Grätzel, Nature, 2013, 499, 316319.

9 Q. Chen, H. Zhou, Z. Hong, S. Luo, H.-S. Duan, H.-H. Wang, Y. Liu, G. Li and Y. Yang, J. Am. Chem. Soc., 2014, 136, 622625.

10 Z. Xiao, C. Bi, Y. Shao, Q. Dong, Q. Wang, Y. Yuan, C. Wang, Y. Gao and J. Huang, Energy Environ. Sci., 2014, DOI: 10.1039/ C4EE01138D.

11 D. Bi, S.-J. Moon, L. Häggman, G. Boschloo, L. Yang, E. M. J. Johansson, M. K. Nazeeruddin, M. Grätzel and A. Hagfeldt, RSC Adv., 2013, 3, 18762.

12 S. T. Ha, X. Liu, Q. Zhang, D. Giovanni, T. C. Sum and Q. Xiong, Adv. Opt. Mater., 2014, 2, 838-844.

13 D. J. Lewis and P. O'Brien, Chem. Commun., 2014, 50, 63196321.

14 H.-S. Kim, C.-R. Lee, J.-H. Im, K.-B. Lee, T. Moehl, A. Marchioro, S.-J. Moon, R. Humphry-Baker, J.-H. Yum, J. E. Moser, M. Grätzel and N.-G. Park, Sci. Rep., 2012, 2, DOI: $10.1038 /$ srep00591.

15 X.-T. Yan and Y. Xu, Chemical Vapour Deposition: An Integrated Engineering Design for Advanced Materials, Springer Science \& Business Media, 2010.

16 S. Colella, E. Mosconi, P. Fedeli, A. Listorti, F. Gazza, F. Orlandi, P. Ferro, T. Besagni, A. Rizzo, G. Calestani, G. Gigli, F. De Angelis and R. Mosca, Chem. Mater., 2013, 25, 4613-4618.

17 H. Yu, F. Wang, F. Xie, W. Li, J. Chen and N. Zhao, Adv. Funct. Mater., 2014, DOI: 10.1002/adfm.201401872.

18 H. Mehrer, Diffusion in Solids: Fundamentals, Methods, Materials, Diffusion-Controlled Processes, Springer Science \& Business Media, 2007.

19 G. E. Eperon, V. M. Burlakov, A. Goriely and H. J. Snaith, ACS Nano, 2014, 8, 591-598.

20 A. Dualeh, N. Tétreault, T. Moehl, P. Gao, M. K. Nazeeruddin and M. Grätzel, Adv. Funct. Mater., 2014, DOI: 10.1002/ adfm.201304022.

21 D. Weber, Z. Naturforsch., B: Anorg. Chem., Org. Chem., 1978, 33, 1443-1445.

22 N. J. Jeon, J. H. Noh, Y. C. Kim, W. S. Yang, S. Ryu and S. I. Seok, Nat. Mater., 2014, 13, 897-903.

23 C. Momblona, O. Malinkiewicz, C. Roldán-Carmona, A. Soriano, L. Gil-Escrig, E. Bandiello, M. Scheepers, E. Edri and H. J. Bolink, APL Mater., 2014, 2, 081504.

24 Z. Xiao, Q. Dong, C. Bi, Y. Shao, Y. Yuan and J. Huang, Adv. Mater., 2014, DOI: 10.1002/adma.201401685. 